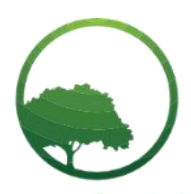

Research in Business \& Social Science

\title{
Effects of organisational culture on strategy implementation in water boards in Kenya
}

Lamet K. Maika®(a), Kevin Wachira(b)

\begin{tabular}{l} 
A R T I C L E I N F O \\
\hline Article history: \\
Received 28 March 20 \\
Received in revised form 05 May 20 \\
Accepted 12 June 20 \\
\hline Keywords: \\
Culture, Strategy Implementation, \\
Teamwork, Stability, Results oriented \\
and Rsik Taking \\
\hline JEL Classification: \\
L19
\end{tabular}

\begin{abstract}
A B S T R A C T
The main objective of the research study was to determine the effects of organizational culture on success of strategy implementation in Water Boards in Kenya. Descriptive statistics data analysis method was applied to analyze data and presented in frequencies, percentage mean, standard deviation, and chi-square results. Finally, multiple linear regression model was employed to establish the significance of the independent variables on the dependent variable. The findings are presented using tables and charts. The study findings showed that in overall the organization culture influences $73 \%$ of change in strategy implementation in the water boards in Kenya. This means that there is a significant relationship between the strategy implementation and the culture of waterboards. Study recommends that; there is need for the waterboards management to encourage employees work together and they need to involve employees in the decision making, organization need to create room for creativity and does not follow rules because although it gives results it also limits the employee's decision making capacity and there is need for employees to be encouraged to be creative and innovative in taking risks.
\end{abstract}

(C) 2020 by the authors. Licensee SSBFNET, Istanbul, Turkey. This article is an open access article distributed under the terms and conditions of the Creative Commons Attribution (CC BY) license (http://creativecommons.org/licenses/by/4.0/).

\section{Introduction}

This study seeks to examine effects of organizational culture on strategy implementation in Water Boards in Kenya. This is because many organizations continue to record high failure rates in the implementation of their strategies. This is caused by the failure of paying attention to both the internal and external environmental forces affecting the organization. The question of successful implementation of strategies remains an unaddressed challenge in many organizations Mehdi, (2010). According to Miller cited in (Gachie, 2014), organizations unsuccessfully implement about 70 per cent of their unique strategies owing to poor organizational culture. Previous researches on strategy have constantly acknowledged organization culture as an element affecting strategy implementation (Isaboke, 2015; Gachua \& Orwa, 2015; Abok, et al., 2013; Muthoni, 2012; Wanjiku, 2012). However, these studies have not given attention to the Water Boards. It can be noted from literature that only organizations which fully implement strategies achieve good records on effective strategy implementation and other areas of organizational performance. Despite all this, only a few studies indirectly focused on organizational culture and its effect on strategy implementation Ahmadi, et al, (2012). This study therefore aimed to fill the missing knowledge gap by determining the effects of organizational culture on success of strategy implementation in Water Boards in Kenya.

Successful implementation of strategies depends on performing excellent job by building and strengthening competitive capabilities through motivation and reward of people in a strategy supporting manner all which is a dictate of a well-built organization culture Smith, (2011). The real value of a strategy can only be recognized through implementation, the ability to implement a strategy is more vital than the quality of the strategy itself (Kiplagat, 2014). According to Bell, Dean, and Gottschalk (2010), strategy execution is commonly the most complicated and time-consuming part of strategic management, while strategy formulation is primarily an intellectual and creative act involving analysis and synthesis.

* Corresponding author. ORCID ID: 0000-0002-1309-5040

(C) 2020 by the authors. Hosting by SSBFNET. Peer review under responsibility of Center for Strategic Studies in Business and Finance. https://doi.org/10.20525/ijrbs.v9i4.697 
According to Zaribaf and Bayrami (2010), the majority of large organizations had problems with strategy implementation. The literature supports the view that unlike strategy formulation, strategy implementation cannot be achieved by top management alone; it requires the collaboration of everyone inside the organization and, on many occasions, parties outside the organization. While formulating a strategy is normally a top-down endeavor, implementing it requires simultaneous top-down, bottom-up, and across efforts (Zaribaf and Bayrami, 2010). This is why the culture of organization plays a great role. Culture is so difficult to manage; it is often overlooked yet over $30 \%$ of mergers fail because of culture incompatibility. Culture clash was blamed for the failure of the joint venture between American Corporations AOL and Time Warner. The acquisition of Compaq by Hewlett also failed due to differences in varying organizational cultures Jacobsen, (2012). Therefore, aligning the company's strategy implementation process with its organizational culture reduces the disruptive nature of the change, but also builds support for the changes being implemented Roll, (2014).

According to Dunlop, Firth \& Lurie (2013), studies consistently show that many strategies fail in the implementation phase. The root of the problem may be traced to three factors: a failure of translation, a failure of adaptation, and a failure to sustain change over the long term. A dynamic approach to strategy implementation can help overcome the limitations of the traditional administrative approach that serves as a breeding ground for these failures.

Organizational culture is a collective behaviour of people who are part of an organization and it is formed by the organization values, visions, norms, working language, structures, codes, beliefs and customs Schein, (2004). Organizational culture therefore seems to have a significant influence on organization's strategy Van Buul, (2010). Organizational culture has the ability to shape organization's capacity for receptiveness to change as well as the ability to nurture the speed and effectiveness with which things are done which calls for skills and competencies of the respective managers which is required for strategy implementation (Ayiecha \& Senaji, 2014). The greatest interest among many organizations currently is the need to improve performance. In this regard, the ability of an organization to improve performance is largely predicated upon the organizations interaction with effective and productive culture (Minkov \& Blagoev, 2011). In order to increase the ability for organizational culture to be effective towards enhancing organizational performance there is needs to look at several interrelated dynamics. This includes how employees make the connection between what they do, and how they do it; the clarity of understanding on principles and organizational values; understanding the locus between individual behavior and performance; and how effective planning impacts performance Mbuvi, (2010).

Spector (2011) and Fullan (2011) argue that in strategy implementation, change is inevitable. Likewise, resistance to change is also inevitable since its human tendency to resist change. It is therefore imperative for managers to clearly understand why people prefer status quo and resist change so as to effectively cope with the resistance and enhance the results of the strategy implementation. Also study by Al-alak and Tarabieh (2011) attest that results orientation is important for organizations to compete against one another in the worldwide global market. This understanding will enable the decision makers to align the situation to the intended results. In strategy implementation, this means that as the situation changes during the implementation process, a result oriented organizational culture will keep the strategy implementers on the original goals. Further study on effectiveness of teamwork showed that individuals have the tendency of hiding inside a group. Similar study by Riki (2013) reviewed how effectiveness of a team impact on high productivity in an organization. Vincent (2011), concluded that, in order for organization to improve on its productivity, effective teamwork is necessary across all the departments.

Employee job performance can only be achieved at its best when all the working elements of the organization perform together. Teamwork has been considered as one of the most desired attribute, which an employer wishes to have in modern day organization West, (2012). Teamwork is not always about working in large teams but a sense of togetherness that make an environment termed as team (Farh, Seo \& Tesluk, 2012). Crawford and Lapine (2013) have argued on teamwork dimensions and concluded that, supervisors and leaders are also part of the teamwork as they are responsible for producing better organizational performance so an integration of employees with supervisors is an important element of teamwork. The opposite argument in this regard comes from the examples of companies like McDonalds and Toyota who are rewarding their employee's in-group work orientation and market leaders in their respective industries. Teamwork has been utilized in such sectors as core competency resulting in a sustainable competitive advantage over the years (Talib, Rehman \& Qureshi, 2013).

According to Ashby et al (2012), the concept of risk culture has grown steadily since the Global Financial Crisis (GFC) of 2008. The term did not appear much in literature prior to the GFC. Risk culture is therefore an emerging terminology which encapsulates a company's risk appetite, tolerance and risk management practices as demonstrated by its employees. Several researches have been carried out on different aspects of strategy implementation in both the private and public service firms in Kenya. The scholars include (Koskei, 2003); (Nabwire, 2014); (Ndiso, 2015) among others. Fewer researchers like Kemboi (2013) focused on strategic plan implementation in state corporations. Amrule (2013) identified that little research has been carried out in developing countries in the area of strategy implementation and further investigations needs to be carried out especially in developing countries like Kenya where the knowledge gap is glaring. Therefore, this study will be undertaken to fill this knowledge gap by increasing knowledge on the culture and strategy implementation in Water Boards in Kenya.

The Water Services Regulatory Board (WASREB) was created to regulate and monitor the provision of water services through setting of standards, development of guidelines, and issuance of licenses to Water Services Boards. Water Services Boards (WSBs) were created to take full responsibility for the provision of water services. This is done through signing of Service Provision Agreements 
(SPAs) with Water Service Providers (WSPs). According to the Act, WSBs are the legal owners of water and sewerage assets in their areas of jurisdiction in the 47 counties in Kenya. As such, they are responsible for the planning, development and expansion of water and sewerage services. They contract water and sewerage services provision to water service providers and monitor service delivery. They also have powers to lease assets, from their owners, for water service provision (WASREB, 2008).

Under the Water Act 2002, WSBs cannot provide services directly, so they have to enter into contract with Water Service Providers (WSPs) through signing Service Provision Agreements (SPAs). WSPs are the ones directly in contact with consumers for purposes of water and sewerage services provision. Currently, over 90 WSPS have signed SPAs with various WSBs (WASREB, 2008).

Despite the role played by WASREB, Kenya is classified as a chronically water scarce country. This scarcity is attributed to a rapidly growing deforestation, population, urbanization, and industrial production and other socio-economic activities. According to Kenya's National Water Services Strategy for 2007 - 2015, only 60 per cent of households in urban areas have access to safe water. In lowincome settlements where a majority of the urban poor live, only 20 per cent of the population have access to safe water, exposing them to relatively high tariffs charged by water vendors. The water Act 2002 provides for Integrated Water Resources Management along the River Basin that is the best practice worldwide and in accordance with Dublin Principles. Prior to reforms in the water sector, water supply and sanitation and water resources management in Kenya faced huge challenges among them being institutional weaknesses, inadequate funding, conflicts due to overlapping roles and responsibilities of key public sectors in the water Act. The constitution of Kenya 2010 recognizes water and sanitation services as a basic right.

\section{Literature Review}

\section{Theoretical Review}

This study was based on; Bourgeois and Brodwins Five Models of Strategy Implementation and Open Systems Theory. This section discusses theories with the aim of building an understanding of culture and strategy implementation.

\section{Bourgeois and Brodwins Five Models of Strategy Implementation}

Bourgeois \& Brodwin (1984) categorize strategy implementation into five models, namely; commander model, change model, collaborative model, cultural model, and coercive models. In the commander model, the general manager carries out exhaustive period of strategic analysis, makes strategic decisions and presents it to top managers and instructs them to implement and the commander waits for the results. The model divides the organization into thinkers and doers. The general manager, commander has a great deal of power and access to complete information and is insulated from personal biases and political interferences.

While in the change model, after making strategic decisions, the general manager plans a new organizational structure, makes personnel changes, new planning, information measurement and compensations systems and cultural adaptation techniques to support the implementation of the strategy.

The collaborative model involves the management team in the strategic decision-making process, where the general manager employs group dynamics and brainstorming techniques to get managers with different opinions to provide their inputs to strategy making and implementation. The cultural model, the key questions is, "how can I get my whole organization committed to our goals and strategies. It takes the participative elements to the lower levels of the organization as an answer to this question. The general manager guides the organization by communicating his or her vision and letting design their work in alignment with the vision.

Finally, in the coercive model the strategy comes upward from the bottom of the organization, as opposed to top-down. The general manager's role is to define the organization's broad purposes to encourage innovation and select judiciously from among those projects or strategy options that come to his/her attention. This model provides a good foundation on looking at the culture and strategy implementation in water boards Companies in Kenya in view of people's involvement or just carried out by a Commander(s) at the top. One key observation from strategy implementation frameworks is that the strategy itself is not part of the framework. This model will be relevant since study looks at how teamwork culture influences strategy implementation in water boards. This theory applies in this study especially in teamwork, stability, risk and results cultures and therefore this is one of key theory in the study.

\section{Open Systems Theory}

All firms operate within an environment. The theory was developed by a Hungarian biologist called Ludwig Von Bertalanffy in (1928). The foundation of systems of theory is that all the components of an organization are interrelated, and that changing one variable might affect many others, or if one sub-system fails, the whole system is put in jeopardy. In this regard, organizations are viewed as open systems, continually interacting with the environment. These parts that share feedback among each other can be looked as consisting of four aspects namely: inputs which comprise resources such as raw materials, money, technology, and people; processes, such as planning, organizing, motivating and controlling; outputs such as products and services and enhanced systems productivity. This implies that when one part of the systems is removed, the nature of the system is changed as well. Systems theory helps managers to look at the organization more broadly and recognize the interrelationships among the various parts of the organization and how they are related to each other. 
The environment influences the strategy implementation efforts of the organization. The Open systems theory was developed after World War II in reaction to the earlier theories of organizations such as the human relations perspective of Elton Mayo and the administrative theories of Henri Fayol. Due to this open systems theory come in many taste for example Institutional theorists see organizations as a means by which the social values and beliefs are embedded in organizational structure and expressed in organizational change. Contingency theorists argue that organizations are organized in ways best fit the environment in which they are embedded. Resource dependency theorists see the organization as adapting to the environment as dictated by its resource providers. According to Bastedo (2004), although we have variety in perspectives as provided by the Open systems theories, they share the perspective that an organization survival is dependent upon its relationship with the environment.

Johnson, Scholes and Whittingham, (2008) observed that a business is a man-made system which has dynamic interplay with various elements that include environment, competitors, customers, suppliers, labor organizations, the government and other agencies. He argues that it's a system of related parts working in conjunction with each other in order to accomplish a number of goals for the organization and those of the individual participants.

The open systems theory has significantly adjusted the way we understand organizations and the demands placed on its leadership and or managers. The Water Boards is operating within an environment and they are not independent of the driving factors behind organizational change. Contemporary studies of teamwork, stability, risk taking and stability cultures all benefit from a strong open systems approach to understanding environmental demands and the resulting adaptation in strategy implementation, or lack thereof and therefore this theory is relevant to this study and will be applicable. This theory supports concept of stability and teamwork at work place and therefore will be based on the two variables.

\section{Empirical Review}

\section{Teamwork Culture}

Burke \& Litwin (2007) argue that organizational culture can sometimes be chaotic a nonproductive. For instance, as many organizations try to bring more people into the corporate decision process, lack of a cohesive collective organizational vision can reduce organizational effectiveness. This means that, conflict between perceived culture, desired culture, real culture, and informal culture can reduce an organizations' performance potential Kamugisha, (2013). A study by Rajasekar (2014) investigated the strategy implementation processes followed in a service industry in the Sultanate of Oman. The study proposed seven factors that affect strategy implementation with leadership by far being the most important factor influencing successful implementation strategy in the service sector.

Lindblom \& Ohlsson (2011) in their study stakeholders' influence on the environmental strategy of the firm: a study of the Swedish Energy Intensive stated that depending on the stakeholders' influence, companies will either prefer a more or less proactive or reactive strategy. Management should always perform stakeholder analysis to identify the various types of stakeholders and their needs, issues and concerns that may affect the strategy implementation. A number of studies have been carried out on the effects of various stakeholders on strategy implementation. Rajasekar (2014) undertook a study on the factors affecting effective strategy implementation in a service industry: a study of electricity distribution companies in the sultanate of Oman and identified that management should be very much involved in strategy implementation. Management should always make sure that all processes are streamlines, all activities are coordinated, the organizational structure is aligned, and employees are motivated and committed to strategy implementation. Management should also make sure that they communicate effectively to their employees to enhance the ability of the business to implement and refine its strategy. The leadership style used by management in a given company influences how the chosen strategies will be implemented. Ramashala, Pretorius \& Steyn (2015) undertook a study on effective strategy execution to realize shareholder value: a proposed framework for management stated that shareholders are very much valued and all their recommendations should be included in strategic plans and implementation processes. Answers on questions concerning implementation should be provided to all shareholders so that they can contribute in realizing the company strategy. This will additionally increase company profits and ensure satisfied shareholders. The above case studies have looked at various factors influencing strategy implementation but none has looked at how culture relates to its implementation a gap that this study seeks to fill. Nelson \& Quick (2011) identified four roles that an organization's culture plays, including: providing a sense of identity to members, enhancing the employee commitment, strengthening organizational values and shaping behaviour through a central mechanism. Muya et al., (2012) conducted a survey of Kenyan State Corporations on the relationship between corporation culture and organizational performance. Using a Pearson-product moment correlation analysis, the findings revealed that an organization's values and the resultant performance were strongly related with a value of +0.743 . Organizational culture was measured by several indicators including: employee confidence on an organization's future, internal communication, the management getting to share its business strategies and performance results with all its employees (and if applicable with its clients), a highly disciplined management, use of employees' performance feedback and appraisals and management encouraging and rewarding specific workplace behaviour and workplace harmony. They concluded that an institution's culture could be made very strong and cohesive by sticking to an explicit and clearly set-out principles and values. They also argued that having an influential leader who establishes desirable values, and possesses sincere and desirable commitment to run an organization according to the desirable values and expression of genuine concern for the well-being of an institution's stakeholders can positively and significantly influence an organization's performance. 
Omondi, Ombui \& Mungatu (2013) conducted a study with the purpose of finding out the determinants of strategy implementation by the international reproductive health (RH) nongovernmental organizations (NGOs) in Kenya for attainment of MDG 5 by 2015. The study established that there is a significant statistical association between communication of the strategy to the implementers and stakeholders and ability to implement with about 55 per cent of the respondents agreeing that communication affects strategy implementation. This contrasts with study done by Mucai \&Messah (2010) which concluded that communication of the strategy influences implementation of strategic management plans through the preference of institutional leadership and Board of Governors. Another study by Mbaka \& Mugambi (2014) sought to review the factors that affect strategy implementation in the Water Sector in Kenya. The study identified strategy formulation process, relationship among different departments and different strategy levels, executors, communication, implementing tactics, consensus, commitment, organization structure, employees and inadequate resources as some of the factors that affect strategy implementation.

Ongong'a (2014) conducted a study on the factors influencing strategy implementation at Kenya Commercial Bank in Kenya and stated that participation and interaction by top management leads to commitment of employees to the firm's strategies and goals which in turn ensures a successful strategy implementation. A manager has the ability to delay implementation timelines, re-direct strategies, reduce or sabotage the quality of effort exerted to the implementation. The CEO should also have the ability to motivate his/her employees and recognize their efforts with rewards. Committed top managers will always encourage initiative from the middle and lower level managers. Managers should integrate all the role of employees in different departments. Individual leadership traits also play a huge role in overseeing effective strategy implementation.

\section{Stability Culture}

Globally, SHRM (2012) observed that if an organizations culture which is akin to its soul is to progress its general performance and efficiency, then its culture has to be strong and able to offer a tactical competitive advantage while its philosophy and values have to be extensively shared and strongly upheld to enhance effective implementation of its strategies. Mohammad, Uddin, Huq, \& Saad (2013) conducted a study targeting the impact of organizational culture on productivity and performance of employees working in the telecommunication sector within Bangladesh in South Asia. The findings of the study indicated that organizational culture contains a significant and positive impact upon employee's productivity, performance, and the overall performance of the organizations in developing countries.

Stafford\& Miles, (2013) had argued that an organization needs to be in touch with its culture to be able to control its performance. Literally, this means that an organization has to assess its own structure, beliefs, values, and assumptions that inform the organizations way of doing things. As such, this will not only allow the organization to remain relevant, but to identify precipitous factors inherent within its culture that are god for performance, and those that are bad for performance. Hartnell, Amy \& Kinicki (2011) carried out a study on organizational culture and its effectiveness, a meta-analytic enquiry of the competing values framework's theoretical. Their findings were that there is a significant correlation between organization culture and its effects on strategy implementation. This controverts the theme of the current study which is testing on the effect of organizational culture on a different outcome which is effective strategy implementation. Mushtaq \& Bokhari (2011) concluded that there is sufficient evidence linking cultural traits and organizational effectiveness. He found that mission is the most important cultural trait that today's organizations need to focus on. The other cultural traits that are important include involvement, adaptability and consistency in order of importance. A study carried out by Schein (2009) revealed that organizational culture carries critical forces that need to be considered in strategy implementation.

In order to survive in changing business environment, organizations must adopt new strategies. Mbwaya (2012) did a study on strategic change management practices at Barclays Bank of Kenya. He identified the importance of strategic planning, timely planning and stakeholderse involvement in reducing resistance to change. The findings were that there is no universal approach to the strategic change management and therefore its practices keep evolving from time to time depending with- the changes in the environment.

Nganga (2014) studied strategic management practices and performance of Dyer \& Blair Investment Bank in Kenya. Mugo (2014) studied strategic management practices and performance of Kenya Revenue Authority. Both studies identified a positive relationship between strategic management practices such as visible leadership, effective customer service, customer awareness to good performance. Strategic planning was found to lead to effective company performance. Muogbo (2013) carried out a research on the force of strategic change management on organizational development and the advancement in manufacturing firms in Anambra state in Nigeria. The conclusion was that though strategic change management is not a widespread business doing among the manufacturing firms in Anambra State, it is a veritable tool for improving the competitiveness, performance standards, and structural expansion of manufacturing firms in Anambra State and Nigeria in general. Kimaita (2010) did a research in 2010 on strategic change management practices in the Teachers Service Commission in Kenya. She discovered existence of many changes that cause disputes in various institutions. These are information technological innovations, political, social-cultural and consumer behavior. Due to these aspects, multiple organizations are necessitated to improve their business procedures to endure in the competitive environment. It implies that they have to start strategic changes to make parallel their business strategies to the current environment and matching the resources and doings of the company to those of the environment.

Gachohi (2014) was involved in a study focusing on 54 NIC-Bank management and employees in head office and all the sixteen branches. The main agenda of the research was to establish the problems the commercial banks face, which need strategic change 
management. The conclusion was that strategic alterations happened in various banks. These strategic alterations were caused by internal aspects, external reasons and the technological factors.

Muthoni (2012) in her study on Effects of Organizational Culture on Implementation of Strategy within Commercial Banks operating in Kenya found that $75 \%$ of commercial banks in Kenya uphold culture of entrepreneurship, dynamism, and creativity at work. Majority of these commercial banks in Kenya have adopted the cultures that are flexible in dynamic work environments. This culture is grounded in supportive strategy values, together with practices and other behavioral norms add to the effectiveness and power of a company's ability to strategy execution effort. The study which used both primary and secondary data showed that majority of commercial banks are more interested in upholding their organizational cultural values than work.

\section{Risk Taking Culture}

Farrel \& Hoon (2015) also came to the conclusion that an organizational risk culture is a crucial factor which helps to ensure that doing what is right triumphs over doing whatever it takes. To support this assertion, they cited a recent KPMG survey which covered almost 500 bank executives. The survey revealed that almost half (48 percent) of respondents indicated risk culture as a leading contributor to the credit crisis. Institutions with a strong risk culture history managed to weather the storm. More than half (58 percent) of corporate Board members and internal auditors surveyed by the survey said that their company's employees had little or no understanding of how risk exposures should be assessed for likelihood and impact. One-third of the respondents also mentioned that key leaders in their organization had no formal risk management training or guidance.

Farrel \& Hoon (2015), argue that business executives should pay more attention to risk culture. They contended that, “organization's with inappropriate risk cultures will inadvertently find themselves allowing activities that are totally at odds with stated policies and procedures or operating completely outside these policies. Davidson et al. (2012) say risk culture is the responsibility of the leaders. They mean leaders need to make the culture strong, by giving their workers enough responsibilities. The article describes that risk culture should be a part of the whole culture of the company, shared by everyone. The employees are the most important people because they are the ones that execute the company. By this, they are also the ones that create possible risks. A culture of risk management changes the way employees think about their responsibilities in the organization. Chintrakarn, Jiraporn \& Tong (2015) show this importance by proving the influence of the CEO on risk-taking. Their finding is that: relatively less powerful CEOs exhibit risk aversion, resulting in less risky strategies. However, when the CEO has his power consolidated beyond a certain point, he is less likely to compromise with other executives, leading to less moderate decisions and riskier strategies.

Sung \& Choi (2014) examine this encouragement by employee empowerment can for example be a reason for more innovations in the company. To innovate is risky, but can be extremely helpful for the company results. They argue that it is important to stress in the training sessions that mistakes may be made, there can be learned from it. This is also something that needs to be part of the corporate risk culture; risks may be taken, by everybody. Lumpfer \& Fuchs (2011), stress the importance that the sessions are based on the job of the person, the more customized the training the more it will attain the attention. The article also mentions that risk training should be included into general learning and development issues, as by doing that, people will be more aware of the risks in their daily tasks.

\section{Results Oriented Culture}

A study by Al-alak \& Tarabieh (2011) attests that results orientation is important for organizations to compete against one another in the worldwide global market. They posit that due to rapid changes facing organizations, results orientation requires a clear understanding of both the present and future dynamic conditions within and outside the organization. This understanding will enable the decision makers to align the situation to the intended results. In strategy implementation, this means that as the situation changes during the implementation process, a result oriented organizational culture will keep the strategy implementers on the original goals. It offers the edge to adjust to change while still focusing on the intended outcome.

In Africa, 57\% of food manufacturing firms in Zimbabwe failed to successfully implement their strategies for the past three years due to poor organizational culture, Allio (2005). In these regard a strategically relevant organization culture remains central as a unifying and encouraging factor to be considered in the implementation process as its absence can lead to poor integration of activities and diminished feelings of ownership and commitment which eventually compromises on successfully implementation of strategies Ahmadi, Salamzadeh, Daraei, \& Akbari, (2012). Ahiabor (2014) conducted a study that aimed to investigate the impact of documented corporate culture on the ultimate productivity of firms in Ghana by using the case of Vodafone, a telecommunication firm. Based on the research study findings, Ahiabor (2014) concluded that there exists a positive correlation between corporate culture and productivity of any organization as evidenced by the numerous awards and accolades won by Vodafone. Closer to Kenya, Dahie, Takow, Nur \& Osman (2016) conducted a study to assess the impact of employee performance and organizational culture in the performance of telecommunication firms located in Mogadishu, Somalia. The findings of the study revealed that competitive culture, linked to entrepreneurial culture, and read with consensual culture of an organization has an effect not only on the productivity of employees but also the general performance of an organization.

Mbaka \&Mugambi (2014) conducted a study on strategy implementation in the Water Sector in Kenya through descriptive design. The study studied various secondary data reports on how various water projects were implemented. The findings show that strategy implementation in the water sector was affected to a large extent by the level of management support, inadequacy of resources and 
technical expertise among staff. The findings further indicated that strategy implementation was affected by the type of management leadership and the communication effectiveness.

\section{Strategy Implementation}

Strategy is the most important planned decision whose influence on business operations of an enterprise is crucial. It is in the heart of the strategic management concept that is the concept of company management by means of strategy. Strategy represents a basic way of achieving the goals of an enterprise, Yarbrough, Morgan \& Vorhies (2011). It shows how enterprise harmonizes its abilities and resources with the requirements of ever-changing environment in which it operates. Through its strategy, company strives to use all the options and avoid all the dangers in its environment, but also to use all the advantages and minimize the weak nesses with respect to competitions. Strategy is today observed dynamically, as a continual process. Hence, it is regarded that strategy is formed, rather than formulated, Yarbrough, Morgan \& Vorhies (2011). The following are usually quoted as basic components of strategy: 1. Business area in which the company will perform its business activities; 2 . the way in which competitive advantage in the chosen business areas is achieved; 3 . allocation of resources on the chosen courses of action. In other words, through strategy, as a planned decision, a company first chooses the business area in which it will perform its business activities, and it usually does so within the frame of the product/market matrix. Hence, specific way in which competitive advantage over the competitors will be achieved in the chosen business areas is determined by the strategy. While determining a competitive strategy, an enterprise must make two choices. The first choice refers to the width of the competitive scope: to cover all market segments within the chosen business area or to focus on just one market segment. The second choice refers to the way in which an enterprise achieves the advantage over its competitors: by a leading position with respect to costs or by differentiation with respect to the competition, Yarbrough, Morgan \&Vorhies (2011). Finally, resources (material, financial and human) are apportioned through implementation of strategy, so they are allocated to individual activities with the purpose of acquiring competitive advantage in the chosen business areas.

\section{Conceptual Framework}

A conceptual framework describes the relationship between the research variables. Sekeran (2003) argues that a variable is a measurable characteristic that assumes different values among subjects. An independent variable is that variable which is presumed to affect or determine a dependent variable (Dodge, 2009). A dependent variable is a variable dependent on another variable like the independent variable. A dependent variable is the variable which is measured in the research study (Kothari, 2006). Figure 1 shows the conceptual framework adopted by the research study. In the conceptual framework, the independent variables are; Teamwork, Stability, Risk Taking and Results Oriented Culture and the dependent variable is Successful Strategy Implementation.

\section{Independent Variables}

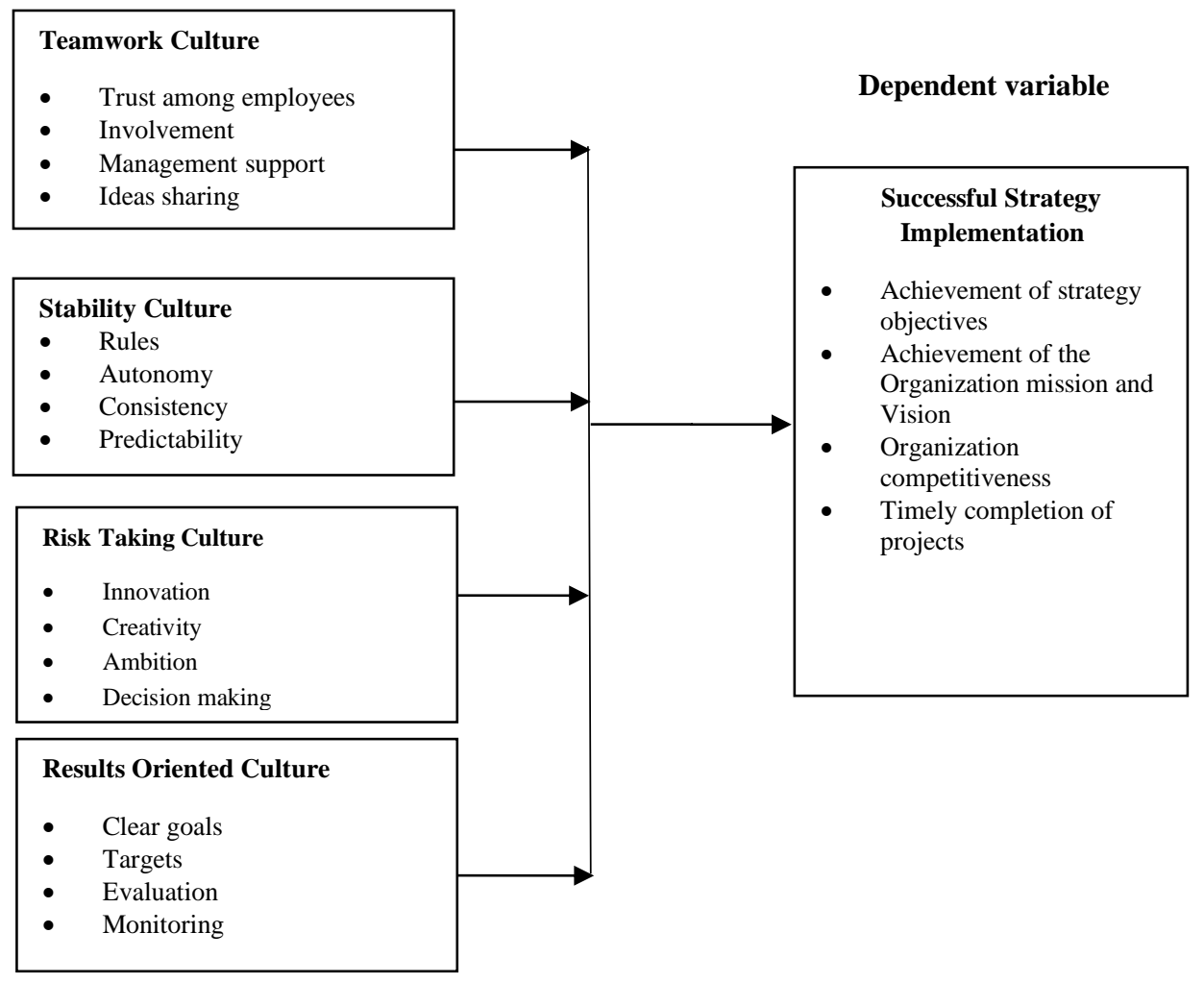

Figure 1: Conceptual Framework 


\section{Research and Methodology}

\section{Sampling Design}

The study adopted a descriptive research design. Descriptive studies use the logical methods of inductive-deductive reasoning to arrive at generalizations, descriptive studies employ methods of randomization so that error may be estimated when inferring population characteristics from observations of samples and in descriptive research. The study considers this design appropriate since it facilitated obtaining information from few respondents in order to have a general view of the nature and characteristics of the effects of organizational culture on success of strategy implementation in Water Boards in Kenya.

This study utilized the proportional stratified random sampling technique by dividing the population into three stratas. The desired sample size in each strata was arrived at through systematic random sampling by calculating proportionately according to the percentage it contributed to the target population. This study target population comprised of a total of 180 management and line staff working in the eight Water Boards in the Ministry of Water and Sanitation. A sample population of 100 was arrived at by calculating the $50 \%$ of target population of 180 with a $95 \%$ confidence level and an error of 0.05 basing on Mugenda and Mugenda (2008) $30 \%$ being adequate sample.

\section{Data Collection}

Data was collected using self-administered questionnaires. The questionnaire was in five sections. The first section was about the attributes of the respondents and the rest of the sections was about the study variables. All the items of the questionnaires were measured using a Likert scale consisting of five scores from 1= "Strongly Disagree" to 5 = "Strongly Agree".

\section{Data Analysis}

The use of semi structured questionnaires facilitated gathering of both quantitative and qualitative data. Quantitative data analysis method was therefore being applied to analyze quantitative data through calculating responses frequencies, percentages and means. Further inferential statistics was done using chi-square was used to establish significance of variables and a multiple regression model to establish the relationship between the research variables. The findings were presented using tables and charts. Correlation analyses were also being conducted to test the strength of relationship between the research variables and Analysis of Variance (ANOVA) was used to test the significance of the relationship between research variables. Statistical Package for Social Sciences (SPSS) version 25 and windows' Microsoft excel programs were tools used in data analysis.

\section{Result and Discussion}

\section{Respondents}

Response rate equals to the number of people who completed the semi-structured questionnaires divided by the total number of people in the entire sample, multiplies by (100) one hundred Fowler, (2004). From the 90 issued questionnaires 71 of them were returned. This represented $78.9 \%$ overall successful response rates. The $78.9 \%$ response rate was attributed to the use of selfadministered questionnaire. Respondents were also assured of confidentiality of the information provided.

\section{Effect of Teamwork Culture on Strategy Implementation}

From the survey $45.1 \%$ of the respondents agree that the water boards is a very personal place. It is like an extended family and people seem to share a lot of personal information and features (involvement). This was supported by Mbaka and Mugambi (2014) study which found that strategy formulation process adopted is affected by relationship among different units/departments and different strategy levels, models applied, communication, implementing tactics, consensus, commitment, organization structure, employees and inadequate resources. Also, this is in line with the work of Alvesson (2011) who postulated that for an organization to successfully implement any strategy it formulates, all staff should work together as a team to enhance smooth flow of all processes and operations involved in achieving the set goals and objectives in any formulated strategy. The respondents were however neutral on whether customer is the main focus on the daily activities of the organization and whether communication modes in the organization are simple and clear.

It was revealed that $60.6 \%$ of the respondents agree that there is trust among employees at my work place, this is supported by MingChuan, Qiang, Sang-Bing and Yi (2018) who found out that creativity positively predicted innovative behavior through organizational trust, and an innovative climate via organizational trust. According to $60.6 \%$ agree that there is diversity of opinion is respected at water boards. Congruent to above, Blacklock (2012) found out that for organisations to improve their flexibility capability, flexibility is no longer confined to the working relationship between an employee and their manager. It involves many parts of the organisation working together to create a successful transformation. Whether it be creating new processes and systems around work; requiring managers and employees to change the way they work; or implementing new infrastructure and technology, organisations need to create a holistic, integrated approach that involves all key stakeholders.

Also it was also revealed that $52.1 \%$ of the respondents agreed that in the water boards there is free and open sharing of ideas and resources at work place. In line with above, Mbaka and Mugambi (2014) agree that relationship among different units/departments 
and different strategy levels, models applied, communication, implementing tactics, consensus, commitment, organization structure, employees and inadequate resources affects ideas sharing. Marginson (2012) agrees that strategy implementation begins from gaining the commitment of a group by way of coalitional process of decision-making, or from full coalitional contribution of implementation staff through a tough corporate culture.

On management support according to $47.9 \%$ they agree while $43.7 \%$ disagree that the leadership in the water boards is generally considered to exemplify mentoring, facilitating, or nurturing at workplace. Wiseman (2010) is in agreement with these findings since he postulated that leading by example is the only way the followers are able to operate in line with the Organization's vision and mission. While on management style according to survey results $50.7 \%$ of respondents agree that the management style in the organization is characterized by teamwork, consensus, and participation. This is in line with Caldwell, Chatman, Lapiz, Self and Williams (2010) study which found out that top management effectiveness at various levels of the organization are key in the successful implementation of strategies. The main challenge in implementation of strategies is ensuring that employees commit and direct their capabilities in the business by understanding the new strategy. Therefore, the importance of top management involvement outweighs any other factor in strategic implementation (Rajasekar, 2014). From the 8 interview of water boards CEOs 6 of them were available and all $6(100 \%)$ agree that lack of proper teamwork affects strategy implementation in the organization. Goromonzi, (2016) proved that there is a relationship of teamwork and influence between the company strategy and its organizational culture.

\section{Effect of Stability Culture on Strategy Implementation}

According to $93 \%$ of the respondents the water boards places high value in rules. Thompson et al. (2010) suggested that in order to achieve success in implementation of a strategy, motivation of individuals to pursue the set objectives or rules with enthusiasm and further still, modify their duties and job conduct to better fit the requirements of successful strategy execution was important. Spector (2011) and Fullan (2011) conclude that in strategy implementation, change is inevitable and likewise resistance to change is also inevitable since its human tendency to resist change, because it forces people to adopt new ways of doing things. It is therefore imperative for managers to clearly understand why people prefer status quo and resist change so as to effectively cope with the resistance and enhance the results of the strategy implementation.

From this study $76.1 \%$ of the respondents agree that in the water boards, several authorizations are required to make any changes. In support, Rajasekar (2014) established that good strategies are broken down into feasible short term timelines so that the management can track their performance over the short period which helps in informing their further scenario planning and controlling resource allocation for sustained future organization performance. It was also shown that $46.4 \%$ of respondents agree that in their organization activity results can easily be predicted at water boards. Contrary to this Cristian-Liviu (2013) study established that one of the most plausible causes behind organization failure is the resistance to change.

In this study results showed that $69 \%$ of the respondents agree that at the water boards' operates in a very controlled and structured place. Formal procedures generally govern what people do in the workplace. This is contrary to the work of Swanson (2013) who argued that decision-making processes in organizations should not be bureaucratic and the reporting levels should be simplified and co-operation enhanced from lower cadre all the way to top management. This is also supported by Thompson, Thompson, Gamble, \& Strickland (2012) who found out that the structure of the organization is one of the key determinants of effective strategy implementation as it determines the flow of information and how tasks are performed. It promotes communication and continuous feedback to key stakeholders in the organization.

\section{Effect of Risk Taking Culture on Strategy Implementation}

According to $76 \%$ of respondents agree that in the water boards, employees are encouraged to proactively seek out opportunities by taking risks. In relation to risk taking, from survey $84.5 \%$ of the respondents agree that the water boards encourages staff to take calculated risks in solving work related problems. Roomi and Harrison (2010) alluded that when leaders have higher risk-taking, proactiveness and innovativeness, they can stimulate their teams to be more creative during the strategy implementation and product development process. They argue that raising these behaviours in the leader will tend to be accompanied by elevated creativity in teams. Also, congruent to above Jones \& George, (2011) agrees that innovative and adhocracy cultures are flexible and allow room for creativity and risk taking. This helps the strategy implementation process to be carried out fast and efficiently. Abdulsamad, \& Yusoff, (2016) study findings agree managers of firms are today focusing more on achieving risky projects for purposes of increasing organizational profitability. Also firms manage risk and take risk differently in an attempt to minimize its effect on performance.

Also revealed that $76.1 \%$ of respondents support that innovation is highly encouraged in water boards. This is in line with the work of Clayton (2010) who argued that for an organization to be able to implement any strategy in the dynamic environment organizations currently operate in, staff need to be given room to be innovative and creative on how to achieve the set goals so long as their innovations and creative ideas are in line with the organization's goals and objectives.

Also $52.1 \%$ of the respondents agree that in water boards, there is room for making mistakes when trying new ideas. This is agreement with Alireza, Marja and Tauno (2012) findings that found that presenting creative ideas and solutions is encouraged between related organizational staff at different levels. Noting that the possibility of emerging creative ideas in organizational meetings between persons from different organizational levels is low, fostering creativity and innovation techniques can be an ideal solution for successful group meetings. 
Study revealed $46.5 \%$ of the respondents agree that employee ambition is positively encouraged in water boards. In support Speculand (2014) argues that a culture embedded with values and behaviors that facilitate strategy execution promotes strong employee identification and commitment to the company's vision, performance targets, and strategy. In relation to organization dynamism, the findings also showed that $29.6 \%$ of the respondents agree that the water boards are very dynamic entrepreneurial place where people are willing to take risks. In support Gatwiri et al., (2014) found out that organizational processes, organizational culture and organizational structure influence strategy implementation to a great extent. Further Ahmadi et al., (2012) verified that flexible cultures have to do more with policy formation and structural factors in implementation.

\section{Effect of Results Oriented Culture on Strategy Implementation}

In relation to goals, according to $57.7 \%$ of the respondents agree the water boards has long term goals that are very clear. Vähämäki et al. (2011) alludes that that the primary purpose of results based management is to improve efficiency and effectiveness through organisational learning, and secondly to fulfil accountability obligations through performance reporting which means that it influences strategies implementation. Also, in support of above, Divan (2012), agree that strong and unified cultures will approach strategy implementation and affect implementation in a positive manner by aligning goals. They also found out that goals also will create a domino effect in the organization that ensures that all work performed by each individual in the company and work group focuses on performance and on the strategic importance of the company.

Results also showed that $63.4 \%$ of the respondents agreed that water boards are very results-oriented. A major concern is getting the job done. People are very competitive and achievement-oriented. According to $70.4 \%$ of the respondents agree that leadership in the organization is generally considered to exemplify a results-oriented focus. In line with this study, Mbaka and Mugambi (2014) study revealed that show that strategy implementation in the water sector was affected to a large extent by the level of management support, inadequacy of resources and technical expertise among staff. The findings further indicated that strategy implementation was affected by the type of management leadership and the communication effectiveness.

In relation to management styles, survey results showed that $70.4 \%$ agreed that management style in the water boards are characterized by hard-driving competitiveness, high demands, and achievement. Congruent to above, Awadh and Saad (2013) found certain dimensions of culture have been identified so far and research shows that value and norms of an organization were based upon employee relationship. Managers need to relate organizational performance and culture to each other as they help in providing competitive advantage.

\section{Multiple Regression Test}

A multiple was undertaken to test whether there is a relationship between the independent and dependent variables.

\section{Multiple Linear Regression Results oriented culture, Stability culture on strategy, Risk taking culture, Teamwork culture on} strategy

The following multiple regression model was used to test the significance relationship of independent variables against the dependent variable as shown in Table 1.

$\mathrm{Y}=\mathrm{B}_{0}+\beta_{1} \mathrm{X}_{1}+\beta_{2} \mathrm{X}_{2}+\beta_{3} \mathrm{X}_{3}+\beta_{4} \mathrm{X}_{4}+\varepsilon \mathrm{i}$

Table 1: Model Summary Relationship between Culture and Strategy Implementation

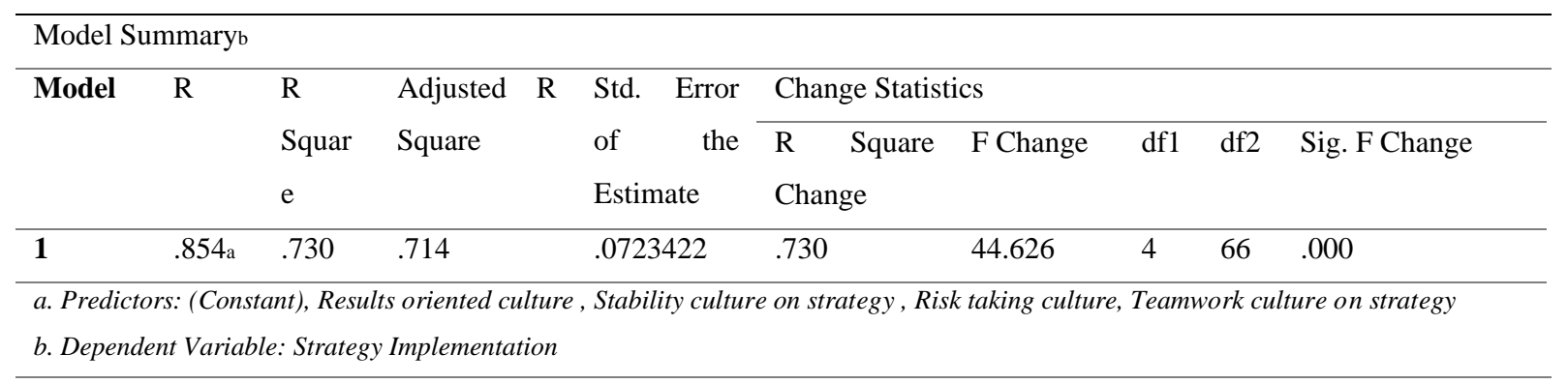

The regression analysis shows a relationship for the 4 objectives indicates, $R=0.854$ and adjusted $R_{2}=0.730$ which shows that the four variables explains $73 \%$ unit change in the strategy implementation can be explained by the change in the four variables as shown in table 1. The study also conducted Analysis of variance (ANOVA) and the results are as shown in Table 2. 
Table 2: ANOVA Relationship between Culture and Strategy Implementation

\begin{tabular}{lllllll}
\hline ANOVAa & & & & & \\
Model & & Sum of Squares & df & Mean Square & F & Sig. \\
\hline $\mathbf{1}$ & Regression & .934 & 4 & .234 & 44.626 & $.000 \mathrm{~b}$ \\
\cline { 2 - 7 } & Residual & .345 & 66 & .005 & & \\
\cline { 2 - 6 } & Total & 1.280 & 70 & & & \\
\hline
\end{tabular}

a. Dependent Variable: Strategy Implementation

b. Predictors: (Constant), Results oriented culture, Stability culture on strategy, Risk taking culture, Teamwork culture on strategy

The results in Table 2, the results showed that the calculated F-statistic was 26.807 meaning that the model was fit in predicting tourism performance in culture. The basis of either rejecting or accepting the null hypotheses was determined by whether the p-value was greater or less than 0.05 . In this study p-value was 0.000 , which was $<0.05$ and therefore the null hypotheses was rejected, which confirms that there is a relationship between the independent and dependent variables hence the null hypothesis

was rejected.

The study further sought to determine the coefficients of the independent variable and the results shown in Table 3 were obtained.

Table 3: Coefficients Relationship between Culture and Strategy Implementation

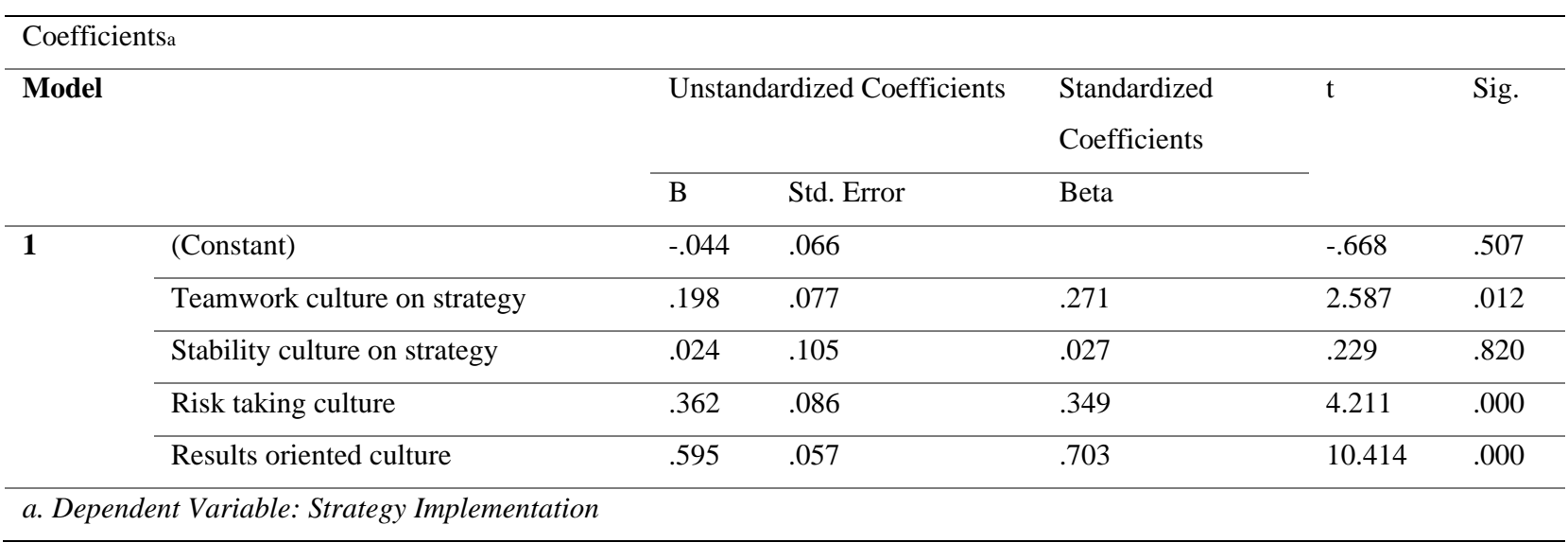

The complete model will be as follows according to this study $\gamma=-0.044+0.271 \mathrm{X}_{1}+0.027 \mathrm{X}_{2}+0.349 \mathrm{X}_{3}+0.703 \mathrm{X}_{4}+0.066$. The analysis evaluated and interpreted the standardized coefficients of correlation (Beta). In estimating the contribution of each independent variable of the study, it was established that all independent variables significantly contributed to a significant variance of implementation at significant level of 0.05 . However, the relative importance of each independent variable(s) was different for each variable. teamwork culture $27.1 \%$, stability culture $2.7 \%$, risk taking culture $34.9 \%$ and results oriented culture 70.3 this means that all the four variables influences on strategy implementations but at a different level.

\section{Conclusions}

The water boards have close teams that work together and they share a lot of information. They trust each other and the team spirit enables them complete their tasks. The management also supports the employees to work as teams. Stability culture has been emphasized in the water boards, they follow rules strictly and hierarchy of decision making is followed by the employees. The water boards are very formal and procedures are formalized.

The water Boards have room that enables employees take calculated risks while solving problems and coming up with new ideas. The employees realize their ambition and create a dynamic workplace.

The water boards put emphasis on results and ensure that the goals of the water boards are achieved. The water boards have agreement with employees that enables them deliver on their goals. Success is defined based on winning by the employees at workplace. 
Based on the study findings the following recommendations were made; There is need for the water board's management to encourage employees work together and they need to involve employees in the decision making. It is important that employees embrace the water boards embrace organizational culture and absorb the shared values. In addition to this top management should provide precise guidelines and direction to encourage and gain commitment from the employees to achieve the company's objectives. Leaders should also be team members since the water board's cultural dimensions that water boards deem to be valuable will impact the way leadership conduct them to achieve a successful strategy execution. It is important for management to understand that cultural dimensions play an important role in defining leadership behaviours. On teamwork, strategy implementation should be a participative process that involves all the water boards' members. Top management can oversee the process, but should involve their subordinates so as to get their input on the proposed strategy. It should also be done continuously through a series of phases which allow enough time for management to evaluate the reception of the strategy by water board's members.

There is need for the water boards to create room for creativity and not only follow rules because although it gives results it also limits the employee's decision making capacity. This is predominantly the reason why organizational culture is held in such high importance in both the academic and business world; it is valuable and if well understood can be utilised to create a sustainable competitive advantage. Therefore management need to focus on fostering and developing organisational culture dimensions, since organizational culture can have a direct impact on good strategy execution.

There is need for employees to be encouraged to be creative and innovative in taking risks. The risk that they take solves problems and comes up with new ideas and ways of doing things. This means that the leaders of water boards need to be cognizant that the organisation culture and practices influence the way leaders and employees behave and what they do such as taking risks and giving the employees room to make mistakes. A large part of the what they do in the water boards involves streamlining resources as well as maximising output this is generally enabled by co-ordination between employees, teams, leaders and departments to achieve success.

The water boards should not put much emphasis on only winning and delivery of goals but also enable employees work together as teams to deliver without caring who wins. Therefore management must foster and develop water board's culture that rewards employees for the successful execution of strategy since it is this aspect that keeps employees motivated to create good processes for sustainable strategy execution and remain committed and therefore creating stable culture that can be emulated.

\section{References}

Abok, A. M. (2014). Factors Affecting Effective Implementation of Strategic Plans in Non-Governmental Organizations in Kenya, JKUAT, Doctoral dissertation.

Aboket, A., Waititu, A., Gakure, R., \&Ragui, M. (2013). Culture's role in the implementation $\quad$ of $\quad$ strategic plans in nongovernmental organizations in Kenya. Prime Journal of Social Science, Jomo Kenyatta University of Agriculture and Technology (JKUAT), Nairobi, Kenya.

Ahmadi, S. A. A., Salamzadeh, Y., Daraei, M., \& Akbari, J. (2012). Relationship between organizational culture and strategy implementation: typologies and dimensions. Global Business and Management Research, 4(3/4), 286.

Akbar, A. S., YasharSalamzadeh, M. D., \&Jamshid, A. (2012). Relationship between Organizational Culture and Strategy Implementation: Typologies and Dimensions. Global Business and Management Research: An International Journal ,4, (3 $\& 4)$.

Al-alak, B. A., \&Tarabieh, S. A. (2011). Gaining Competitive Advantage and Organizational Performance Through Customer Orientation, Innovation Differentiation and Market Differentiation.International Journal of Economics and Management Sciences, 1 (5), 80-91.

Alireza.A. Marja N. and Tauno.K; (2012). Application of Creativity Techniques in the Creation of Organizational Strategies. Int. j. eng. bus. manag., 2012, 4(14). https://doi.org/10.5772\%2F51359

Alvesson, M. (2011). Organizational culture: meaning, discourse, and identity. The handbook of organizational culture and climate, 2nd ed. 11-28. Thousand Oaks, CA: Sage Publications.

Amrule, S. G. (2013). The Role of Strategic Planning in the Performance of Small and Medium Enterprises in Information Communication and Technology (ICT) sectorin Nairobi, Kenya. (Unpublished Dissertation, Jomo Kenyatta University of Agriculture and Technology, Kenya).

Ashby, S., Palermo T., and Power M.. (2012). Risk culture in financial organisations: An interim report. Centre for Risk Analysis. Awadh, A.M., \& Saad, A.M., (2013). Impact of Organizational Culture on Employee Performance. International Review of Management and Business Research, 2

Ayiecha, F. O., \&Senaji, T. A. (2014). Moderating effect of organizational culture on the implementation of turnaround strategy. Journal of Business and Management, 16(4),88-93. https://doi.org/10.9790/487X-16418893

Bastedo, M.N. (2004). Open systems theory. The SAGE Encyclopedia of Educational Leadership and Administration, Michigan: University of Michigan.

Blacklock, P. (2012). CAO Cover Letter to 2012-2013 Recommended County Budget \& 2011-12 Annual Report. Retrieved from http://www.yolocounty.org/Modules/ShowDocument.aspx?documentid=19782

Bourgeois, L.,\& Brodwin, D. (1984). Linking planning and implementation. With B.de/Meyer, R., 682-691. 
Burke, \&Litwin. (2007). The Complete Guide to Mergers \& Acquisitions. San Francisco, CA: John Wiley \& Sons, Inc.

Chintrakarn, P., Jiraporn, P., \& Tong, S. (2015). How do powerful CEOs view corporate risk taking? Evidence from the CEO pay slice (CPS). Applied Economics Letter, 22(2), 104-109. https://doi.org/10.1080/13504851.2014.927565

Crawford, E.R. and Lepine, J.A., (2013). A configural theory of team processes: Accounting for the structure of task work and teamwork. Academy of Management Review, 38(1), 32-48. https://psycnet.apa.org/doi/10.5465/amr.2011.0206

Cristian-Liviu, V. (2013). Organizational culture and strategy: How does it work? An empirical research. Annals of the University of Oradea, Economic Science Series, 22(1), 1690-1696.

Dunlop A. Firth V. \& Lurie R, (2013). Dynamic strategy implementation: Delivering on your strategic ambition. Published by Deloitte University Press.

Farh, C. I., Seo, M.-G., \& Tesluk, P. E. (2012). Emotional intelligence, teamwork effectiveness, and job performance: the moderating role of job context. Journal of Applied Psychology, 97(4), 890-900. https://psycnet.apa.org/doi/10.1037/a0027377

Farrel, J.M. and Hoon,. A (2015). What's your company Risk Culture? National Association of Corporate Directors Directorship.

Fullan, M. (2011). The moral imperative of school leadership. Thousand Oaks, CA: Sage.

Gachie, M. (2014). Corporate strategy implementation in construction industry in Kenya: A case of H-young \& Co. East Africa Ltd, in Nairobi, Kenya (Doctoral dissertation, Schoolof Business, Kenyatta University).

Gachua, M. W., \&Orwa, B. H. (2015). Factors affecting strategy implementation in public universities in Kenya: case of JomoKenyatta university of agriculture and technology.International Journal of Education and Research,3(12).

Hartnell C. A.; Amy Y.O, and Kinicki A. (2011). Organizational Culture and Organizational Effectiveness: A Meta-Analytic Investigation of the Competing Values Framework's Theoretical Suppositions. Journal of Applied Psychology. 96(4), 677694.

Havyer, R. D., Wingo, M. T., Comfere, N. I., Nelson, D. R., Halvorsen, A. J., McDonald, F. S., \& Reed, D. A. (2014). Teamwork assessment in internal medicine: a systematic review of validity evidence and outcomes. Journal of general internal medicine, 29(6), 894-910.

Isaboke, C. M. (2015). Influence of Organization Culture on Strategy Implementation In Selected Universities In Kenya.International Journal of Economics, Commerce and Management United Kingdom,3( 9).

Isaboke, C. M. (2015). Influence Of Organization Culture On Strategy Implementation In Selected Universities In Kenya. International Journal of Economics, Commerce and Management United Kingdom,3( 9).

Jacobsen, D. (2012). 6 big mergers that were killed by culture and how to stop it from killingyours. Retrievedfrom http://www.globoforce.com/gfblog/2012/6/big mergers-that-were-killed-by-culture/

Johnson, G., Scholes, K. \& Whittingham, R. (2008).Exploring Corporate Strategy: Text and Cases. (8th Edition). Prentice Hall.

Kiplagat, V. (2014). Strategy Implementation Challenges In Government Parastatals: A Case of Kenya Revenue Authority (Doctoral dissertation, United States International University-Africa).

Lindblom, A., \&Ohlsson, J. (2011). Stakeholders' influence On the Environmental Strategy of the Firm: A Study of the Swedish Energy Intensive Industry.

Mbaka, R. M. \& Mugambi, F. (2014). Factors affecting successful strategy implementation in the Water Sector in Kenya. Journal of Business and Management, 16(7), 61-68.

Ming-Chuan Yu, Qiang Mai, Sang-Bing Tsai and Yi Dai (2018). An Empirical Study on the Organizational Trust, EmployeeOrganization Relationship and Innovative Behavior from the Integrated Perspective of Social Exchange and Organizational Sustainability.

Minkov, \&Blagoev. (2011). What do Project GLOBE's cultural dimensions reflect? An empirical perspective. Asia Pacific Business Review, 21(3), 12-40. https://doi.org/10.1080/13602381.2010.496292

Muogbo, U. S. (2013). The Impact of Strategic Management on Organisational Growth and Development: A Study of Selected Manufacturing Firms in Anambra State. IOSR Journal of Business and Management, 7(1), 2432. https://doi.org/10.9790/487X-0712432

Mushtaq, R., \&Bokhari, R. H. (2011). Knowledge Sharing: Organizational Culture and Transformational Leadership. Journal of Knowledge Management Practice, 12(2).

Muthoni E. (2012) Effects of Organizational Culture on Strategy Implementation in Commercial Banks in Kenya. Unpublished MBA project, School of Business, University of Nairobi.

Omondi, M. P., Ombui, K., \&Mungatu, J. (2013). Factors affecting effective strategy implementation for attainment of Millennium Development Goal 5 by international reproductive health non-governmental organizations in Kenya. The TQM Journal, 25(5), 507 - 519. https://doi.org/10.1108/TQM-10-2012-0079

Ongong'a, F. O. (2014). Factors influencing strategy implementation at Kenya commercial bank limited in Kenya (Doctoral dissertation, University of Nairobi).

Rajasekar, J. (2014). Factors affecting Effective Strategy Implementation in a Service Industry: A Study of Electricity Distribution Companies in the Sultanate of Oman. International Journal of Business and Social Science, 5(9).

Ramashala, P. A., Pretorius, T., \& Steyn, H. (2015). Effective Strategy Execution to Realise Shareholder Value: A Proposed Framework for Management.

Roomi, M. A., \& Harrison, P. (2010). Entrepreneurial Leadership: What Is It and How Should It Be Taught? International Review of Entrepreneurship, 9 (3), 1-44. 
Schein, E. (2009). The corporate Culture: Survival Guide. San Francisco, CA: Jossey-Bass Publisher.

SHRM. (2012). Organizational Culture: Does a company's culture affect organizational performance and effectiveness from Society for human resource Management. Retrieved, from http://www.shrm.org/TemplatesTool

Smith, E. E. (2011). Perceptions Regarding Strategy Implementation Tasks in Selected Industries: $\quad$ A South African Perspective.International Journal of Business and Commerce, 1(4), 22.

Spector, B. (2011). Implementing organizational change: Theory into practice (International ed.). Upper Saddle River, NJ: Prentice Hall.

Sung, Y. S., \& Choi, J. N. (2014). Do organizations spend wisely on employees? Effects of training and development investments on learning and innovation in organizations. Journal of Organizational Behavior, 35(3), $393-412$. https://doi.org/10.1002/job.1897.

Swanson, Richard A. (2013). Theory building in applied disciplines. San Francisco, CA: Berrett-Koehler Publishers.

Talib, F., Rahman, Z. and Qureshi, M.N., 2013. An empirical investigation of relationship between total quality management practices and quality performance in Indian service companies. International Journal of Quality \& Reliability Management, 30(3), pp.280-318.

Vähämäki, J., Schmidt, M., \&Molander, J. (2011). Review:Results Based Management in Development Cooperation. Riks bankensJubileumsfond.

Van Buul, M. (2010). Successful Strategy Implementation: A job for the internal Auditor? Master Thesis, University of Amsterdam, Netherlands.

WASREB, (2008). A Performance Report of Kenya s Water Services Sub-Sector. Issue No.1.

West, M. A. (2012). Effective teamwork: Practical lessons from organizational research.John Wiley \& Sons.

Wiseman, L. (2010). Multipliers: how the best leaders make everyone smarter New York: Harper Business.

Zaribaf, M., \& Hamid, B. (2010). An Effective Factors Pattern Affecting Implementation of Strategic Plans. 